\title{
Mapeamento e Classificação do Grau de Dificuldade da Trilha do Rancho Caído, Parque Nacional do Itatiaia (RJ)
}

\author{
Mapping and Classification the Degree of Difficulty of the Rancho \\ Caído Trail, Parque Nacional do Itatiaia (RJ, Brazil)
}

Grislayne Guedes Lopes da Silva, Thalita Campos Lima, Léandre Panchaud

\section{RESUMO}

A análise de dados mapeados se tornou uma importante ferramenta de auxílio no gerenciamento dos recursos naturais e urbanos. Em Unidades de Conservação (UC), os mapas servem de apoio aos visitantes e ao próprio manejo dos parques. A difusão da utilização de técnicas de Sistemas de Informações Geográficas (SIG) se tornou essencial para a análise espacial de dados mapeados. Pela relevância do tema, selecionou-se como principal objetivo desse trabalho o mapeamento e desenvolvimento de análises espaciais que permitiram classificar a trilha do Rancho Caído, localizada na parte alta do Parque Nacional do Itatiaia (RJ), quanto ao seu grau de dificuldade. Os procedimentos de sobreposição de mapas (overlays), fundamentados na literatura denominada "álgebra de mapas", constituíram a base metodológica deste trabalho. Para o cumprimento do objetivo apresentado, a trilha do Rancho Caído, objeto de estudo do trabalho, foi mapeada com o uso de um receptor GPS para o levantamento de dados geográficos (registro de coordenadas; marcação de waypoints ou pontos de interesse; e registro de tracklog, o caminho percorrido). Somado a isso foi coletada uma imagem SRTM em fontes secundárias. Os dados vetoriais do percurso da trilha foram exportados do Google Earth e importados para um sistema SIG, o software ArcGis. A partir da imagem SRTM foram criadas classes temáticas de níveis de dificuldade da trilha. Para a classificação dos dados, primeiramente foram elaboradas camadas de informações, georreferenciadas no mesmo sistema de projeção cartográfica, considerando os temas: declividade, recursos hídricos, cobertura vegetal e qualidade do traçado. Posteriormente, as camadas de informação foram reclassificadas e somadas, por meio da operação de sobreposição, constituindo um mapa temático unificado. Dessa forma, o produto final do trabalho foi o mapa temático de níveis de dificuldade da trilha do Rancho Caído. A principal contribuição foi o desenvolvimento de uma metodologia, com embasamento na álgebra de mapas, levando em conta alguns fatores ambientais que podem auxiliar na determinação do grau de dificuldade de trilhas.

PALAVRAS-CHAVE: Trilha; Grau de Dificuldade; Parque Nacional do Itatiaia; Mapas Temáticos; SIG. 


\section{ABSTRACT}

The analysis of mapped data has become an important supporting tool for the natural and urban resources management. In Conservation Units (UC), the maps provide support for visitors and for the park's own management. The dissemination of GIS (Geographic Information System) techniques has become essential for the spatial analysis of mapped data. Considering the relevance of the topic, the mapping and development of spatial analysis were selected as the aim of this study which have enabled to classify the Rancho Caído trail, located at the upper zone of Itatiaia National Park (RJ), regarding to its degree of difficulty. The overlay procedures, founded in literature designated as 'map algebra', have constituted the methodological basis of this study. In order to accomplish the purpose this paper, the Rancho Caído trail, object of this study, was mapped by using a GPS receiver for spatial data collection (recording coordinates; marking waypoints or points of interest; and recording tracklog). In addition, a SRTM image (raster) was collected from secondary sources. The vectorial data of the trail routing were exported from Google Earth and imported into a GIS system, the ArcGIS software. Thematic classes related to the trail degree of difficulty were created from the SRTM image. The first step in data classification was to prepare layers and georeference them in the same cartographic projection system, considering the following themes: slope, water resources, vegetation cover, and quality of the trace. Subsequently the layers were reclassified and summed, through the overlay operation procedure, providing a unified thematic map. As a result, the final product of this work was a thematic map of Rancho Caído trail difficulty levels. The main contribution of this work lies on the development of a methodology, based upon map algebra, taking into account some environmental factors which can help to determine the trail's difficulty levels.

KEYWORDS: Trail; Degree of Difficulty; Itatiaia National Park; Thematic Maps; GIS.

\section{Introdução}

Os Parques Nacionais brasileiros são Unidades de Conservação (UCs) pertencentes à categoria de Proteção Integral, inserida no Sistema Nacional de Unidades de Conservação (SNUC), tendo como principal objetivo a preservação e conservação da fauna e flora, e recursos naturais em geral. Sendo assim é permitido o uso indireto dos recursos naturais, o que inclui as atividades de ecoturismo, com utilização do espaço para o lazer e turismo, em que as trilhas são caminhos de fundamental importância por direcionar os visitantes aos atrativos turísticos e/ou por serem os próprios atrativos. Pela importância que uma trilha possui dentro de uma UC, contribuindo no planejamento e manejo do uso público (COSTA et al. 2008), e a necessidade de oferecer informações seguras aos visitantes, torna-se essencial a presença de orientações a respeito da trilha, o que inclui sinalização, mapas de orientação e a classificação de seu grau de dificuldade.

Com o advento de tecnologias, tais como softwares de geoprocessamento, é possível utilizar ferramentas de análises espaciais para auxiliar nesse processo de planejamento e gestão das trilhas em UCs. O que se observa é uma constante dificuldade das UCs lidarem com o planejamento e manejo das trilhas por não apresentarem materiais adequados e recursos humanos necessários (COSTA, 2006). Consequentemente, uma das carências são os mapas temáticos preparados 
para a visitação em áreas turísticas nos parques nacionais brasileiros, mais particularmente em trilhas, assim, o presente artigo teve como objetivo geral 0 mapeamento e desenvolvimento de análises espaciais que permitissem classificar uma trilha quanto ao seu grau de dificuldade e elaborar mapas temáticos.

Segundo a Federação de Montanhismo do Estado do Rio de Janeiro (FEMERJ, 2014) faz 61 anos que não ocorre uma revisão do grau de dificuldade de caminhadas em trilhas no estado do Rio de Janeiro. Diante desse cenário, selecionou-se como objeto de estudo a trilha denominada "Rancho Caído", localizada no Parque Nacional do Itatiaia (PNI), no estado do Rio de Janeiro. A trilha é caracterizada como travessia, uma vez que se diferencia pela extensão e grau de dificuldade em seu trajeto, como será observado no decorrer do estudo.

Como objetivos específicos definiram-se: o mapeamento da trilha por meio de receptor GPS; a definição de uma metodologia para classificação do grau de dificuldade da trilha, tendo como base a álgebra de mapas; a elaboração de mapas temáticos no software ArcGis, de acordo com os critérios definidos; e a elaboração de um mapa temático final com os níveis de dificuldade da trilha denominada Rancho Caído.

A partir do objeto delimitado, a problemática que motivou 0 desenvolvimento desse trabalho foi definida e se apresenta da seguinte forma: "como as técnicas de SIG e análises espaciais podem ser utilizadas para a classificação e mapeamento de trilhas de modo a contribuir para o gerenciamento, manejo e o uso público das áreas naturais?" A partir desse questionamento, 0 estudo partiu para a reflexão de temas de geoprocessamento e ferramentas que poderiam dar suporte e contribuir para a solução da problemática apresentada, bem como fornecer resultados ao objetivo delineado. Como embasamento teórico do trabalho foram abordados temas que possibilitaram a construção da metodologia de estudo e o alcance dos objetivos almejados.

A utilização das funções de análise espacial disponíveis no Sistema de Informações Geográficas (SIG) ou Geographic Information System (GIS), bem como os operadores e funções para manipulação de dados espaciais contidos na álgebra de mapas, se destacam como ferramentas essenciais para 0 desenvolvimento deste estudo. O SIG possui recursos para analisar os dados geográficos e produzir informações geográficas como mapas, que auxiliam no planejamento e gerenciamento do espaço e dos elementos localizados sobre ele (ROSA et al., 1999).

No decorrer do estudo, observou-se que as metodologias de geoprocessamento desenvolvidas por alguns autores e utilizadas em algumas unidades de conservação a respeito da classificação do grau de dificuldade de trilhas levam em consideração apenas a declividade e esforço físico/energia necessária para a realização da trilha (HUGO, 1999; ROCHA et al., 2006; NTO, 2012; BWF, 2014; SCOTLAND'S NATIONAL TOURISM ORGANISATION, 2014; NT, 2014). Esta percepção de que as classificações são subjetivas fez com que o presente trabalho contribuísse com a elaboração de uma nova metodologia para definir os níveis de dificuldade de uma trilha baseado em fatores físicos da trilha. 


\section{Trilhas e Mapas Temáticos}

As Unidades de Conservação (UCs) se destacam como sendo espaços territoriais protegidos buscados por praticantes de ecoturismo no Brasil. Elas foram criadas e implantadas a partir do Sistema Nacional de Unidades de Conservação da Natureza (SNUC), instituído pela lei no 9.985, de 18 de julho de 2000. O SNUC estabelece critérios e normas para a criação, implantação e a gestão das UCs (ICMBIO, 2009).

O primeiro conceito de ecoturismo que se tem notícia foi definido por Ceballos-Lascuráin em 1987 como sendo viagens "a áreas relativamente preservadas com o objetivo específico de lazer, de estudar ou admirar paisagens, fauna e flora [...]" (CEBALLOS-LASCURÁIN, $1987^{1}$ apud KINKER, 2002 p.20). Após essa definição, outros autores buscaram definir o ecoturismo como viagens a áreas naturais com o intuito de lazer e contemplação da natureza, interagindo com ambientes naturais preservados.

Os Parques Nacionais são UCs da categoria de Proteção Integral dos Recursos Naturais que se destinam à preservação de ecossistemas naturais, mas que apresentam parte de suas áreas disponibilizadas para a visitação pública e atividades de ecoturismo, porém sujeitas às normas e restrições do plano de manejo de cada unidade (KINKER, 2002 p.36; ICMBIO, 2009). O Parque Nacional do Itatiaia foi o primeiro a ser criado no Brasil, em 1937 (COSTA, 2002), seguindo o modelo de parques norte-americanos, como o Yellowstone National Park, o primeiro no mundo a ser decretado parque nacional em 1872 (SPINOLA, 2013), no qual era priorizada a proteção das áreas naturais e valorizada a utilização do espaço para lazer, com presença de trilhas e espaços para contemplação da paisagem cênica.

As trilhas fazem parte dessas atividades denominadas ecoturísticas e permitem ao visitante um conhecimento mais pleno e proveitoso das UCs. Além de oferecerem a oportunidade do lazer em áreas naturais e do desfruto de paisagens cênicas, as trilhas promovem a educação ambiental e o sentimento de preservação do meio ambiente, indo ao encontro do conceito de ecoturismo.

Segundo Salvati (2003, p.1), as trilhas podem ser definidas como:

[...] caminhos existentes ou estabelecidos com diferentes formas, comprimentos e larguras, que possuam o objetivo de aproximar 0 visitante ao ambiente natural, ou conduzi-lo a um atrativo específico, possibilitando seu entretenimento ou educação através de sinalizações ou recursos interpretativos.

Para alguns autores, as trilhas podem ter forma circular, de oito, serem irregulares, lineares ou em forma de atalho; serem de graus de dificuldade distintos e classificadas pelo nível da caminhada, desde leve e moderada até pesada; além de serem caracterizadas pela declividade do relevo (ascendentes, descendentes ou irregulares) (ANDRADE, 2003; ROCHA et al., 2006).

Além disso, as trilhas podem ser guiadas (monitoradas) ou autoguiadas (ANDRADE, 2003; ROCHA et al., 2006). As primeiras devem contar com mapas temáticos de indicação do traçado, entre outros recursos cartográficos, bússola ou GPS (Sistema de Posicionamento Global), como ferramentas que auxiliem o 
visitante a realizar o percurso sem a presença de um guia. $E$ as autoguiadas são aquelas que possuem placas de orientação no decorrer do trajeto. Nas UCs em geral costumam haver trilhas que são do tipo travessia, sendo ainda mais essencial a presença de ferramentas de orientação de trajeto, distâncias, altitudes etc.

$\mathrm{Na}$ revisão literária a respeito da classificação do grau de dificuldade de trilhas foi observado que os autores utilizam a declividade como único critério para determinar o nível de dificuldade de trilhas ou a gradação das atividades desenvolvidas no percurso da trilha relacionada ao nível de esforço físico. Este último caso decorre da classificação adotada pela The Adventure Company (2007), que classifica o grau de dificuldade do trajeto da trilha como fácil, moderada ou extenuante (ANDRADAE et al., 2008). As atividades são classificadas do grau A ao grau $E$, sendo o grau $A$ trilhas que não exigem condicionamento físico e grau $E$ trilhas que, além de exigirem condicionamento físico, exigem experiência em montanhismo. No Brasil, esse tipo de classificação é adotada por empresas especializadas em turismo de aventura, utilizando letras para definir a intensidade e números para definir o nível técnico das trilhas (MITRAUD, 2003).

Estudos que utilizam a declividade como critério para a classificação do grau de dificuldade da trilha incluem a classificação realizada por Dias et al. (1986) e Rocha et al. (2006). A classificação de Dias et al. (1986) tem como base a rampa média ao longo da trilha e utiliza as seguintes classes: $0-10 \%$ - leve; $10-20 \%$ média; $20-50 \%$ - difícil; 50-100\% - muito difícil e maior que 100\% - alpinismo. Neste artigo, foi utilizada a classificação proposta por Rocha et al. (2006), que também leva em consideração o critério de rampa média da trilha, propondo as seguintes classes: 0-5\% - relevo plano; 5-20\% - relevo ondulado e 20-70\% - relevo montanhoso.

Entretanto, apesar da importância das trilhas para as UCs, podendo contribuir para o monitoramento de condições ambientais, identificação de problemas de manejo e gestão do espaço (COSTA, 2006), são poucos os parques e demais unidades que oferecem mapas aos visitantes indicando as condições e o grau de dificuldade das trilhas (ROCHA et al., 2006). Assim, os mapas denominados temáticos se fazem fundamentais nas atividades turísticas, servindo de base de orientação e informação aos visitantes. Também são considerados importantes ferramentas para a gestão e manejo de áreas protegidas, como as UCs, e podem inclusive fazer parte do plano de manejo do parque, contribuindo para o seu zoneamento e planejamento adequados.

Os mapas temáticos são definidos basicamente como mapas que representam temas específicos da superfície terrestre, assim pretendem mostrar esses fenômenos utilizando uma simbologia específica (FITZ, 2008). Segundo Archela e Théry (2008), os mapas, como representações cartográficas, são a base de orientação para o planejamento e gestão do território e possuem a função de comunicar sobre um tema. Ainda de acordo com os autores:

O mapa temático deve cumprir sua função, ou seja, dizer o quê, onde e, como ocorre determinado fenômeno geográfico, utilizando símbolos gráficos (signos) especialmente planejados para facilitar a compreensão de diferenças, semelhanças e possibilitar a visualização de correlações pelo usuário (ARCHELA, THÉRY, 2008, p.3). 
Os mapas temáticos, de aspectos ambientais, são aqueles que apresentam uma base topográfica e descrevem um fenômeno geográfico específico, dentre os quais se inclui a declividade, uso do solo, erosão, hidrografia, entre outros. Estes mapas podem ser elaborados não apenas como representação da realidade, mas também podem ser confeccionados por meios de softwares de geoprocessamento que permitam análises espaciais do território. Estes são importantes instrumentos no planejamento ambiental, sendo que os mapas elaborados com o geoprocessamento informatizado e novas tecnologias apresentam informações obtidas com maior qualidade (IBRAHIN, 2014). Nesse sentido, a utilização de funções e operações que permitam a sobreposição de camadas de informações pode contribuir para o enriquecimento das informações.

Por isso, para uma melhor compreensão de assunto abordado, a seguir é apresentado o conceito de SIG, tratando de sua importância para a análise de dados espaciais, assim como são abordados assuntos referentes à modelagem cartográfica e a álgebra de mapas, temas estes que contribuíram para a elaboração da metodologia de trabalho e análise da área de estudo.

\section{SIG e a Álgebra de Mapas}

Segundo Goodchild (1993), existem várias definições para o uso e aplicações do SIG que teve sua origem em dois contextos distintos e no decorrer do tempo foi sendo definido de outras formas por especialistas na área (BURROUGH, 1986; COWEN, 1988; ARONOFF, 1991; CAMARA, 1995). De maneira geral, o Sistema de Informação Geográfica (SIG) ou Geographic Information System (GIS) pode ser definido como um conjunto de hardwares e softwares, informações espaciais e procedimentos computacionais que permitem a análise de dados geográficos, gestão e representação do espaço e de fenômenos que ocorrem nele.

Os SIGs são sistemas destinados ao tratamento de dados geográficos, sendo que esse tratamento abrange a aquisição dos dados, seu armazenamento, manipulação e análise, com a utilização de equipamentos, programas computacionais e recursos humanos especializados (FERREIRA, 2006; CÂMARA et al., 2001), os quais permitem a análise de recursos naturais, transporte, comunicações, planejamento urbano, entre outros (IBRAHIN, 2014).

Um SIG é basicamente composto por uma interface com o usuário, que inclui as informações de entrada no sistema convertendo os dados para integrar um banco de dados geográficos. Os dados de entrada podem estar em forma de tabelas de atributos, mapas, imagens de satélite, entre outros. Neste processo ocorre a modelagem e a integração destes dados geográficos a uma base comum. Os dados do banco geográfico são gerenciados em um sistema de dados espaciais e podem ser consultados e manipulados para a realização de análises espaciais, e conversão em informações geográficas. A partir do processamento dos dados são geradas informações, em forma de relatórios e mapas, como componentes de saída, para visualização e plotagem.

Segundo Câmara et al (2001, p.1): 
O que distingue um SIG de outros tipos de sistemas de informação são as funções que realizam análises espaciais. Tais funções utilizam os atributos espaciais e não espaciais das entidades gráficas armazenadas na base de dados espaciais e buscam fazer simulações (modelos) sobre os fenômenos do mundo real, seus aspectos ou parâmetros.

Os atributos podem ser espaciais, que guardam informações sobre localização, topologia e geometria das entidades; temporais, que se referem à idade, data ou frequência; e temáticos que estão relacionados a outras propriedades das entidades que não são de localização nem temporais (BARBOSA, 1997). Esses atributos passam por operações de análise geográfica, dentre as quais se destacam as operações de manipulação, na qual atributos são classificados em função do seu valor ou atributos diferentes são combinados para se averiguar a correlação espacial. O autor Tomlin (1990) caracteriza estas operações de álgebra de mapas.

De acordo com Goodchild (1992), o SIG possui a capacidade de modelagem dos dados e o processamento de mapas para a solução dos modelos, agregando conceitos do espaço geográfico e estimulando aplicações criativas. Acrescenta-se que para um resultado positivo a validade do modelo, a acurácia dos dados e seus métodos de aquisição são fatores relevantes (BARBOSA, 1997). Conforme Barbosa (1997), o modelo gerado não determina somente como uma variável geográfica vai ser representada, mas também o conjunto de processos e análises que podem ser desenvolvidos a partir do modelo.

Segundo Berry (1993), a modelagem cartográfica é uma evolução da cartografia tradicional, pois o mapa deixa de ser apenas um veículo de informação visual para ser um instrumento de análises de relacionamentos espaciais. A manipulação dos dados cartográficos, por meio de várias técnicas matemáticas e estatísticas, fez com que surgisse uma verdadeira álgebra espacial associada a uma modelagem geográfica (BERRY, 1988).

A álgebra de mapas é considerada uma das principais formas de análise com dados raster ${ }^{2}$, uma vez que duas camadas contendo informações sobre uma mesma área podem ter seus valores combinados para gerar uma terceira camada, com novas informações de interesse para análise. Em análises ambientais o modelo raster costuma ser o mais utilizado por permitir a representação de elementos de variação contínua no espaço, como altitude, clima, entre outros.

Cada camada de mapa possui suas informações espaciais específicas e a resolução da camada descreve a unidade da observação espacial relacionada à dimensão da célula unitária da representação matricial cartográfica. "Esta célula unitária, definida pelo par de coordenadas cartesianas e denominada localização, é a menor unidade do espaço cartográfico, para a qual os dados são coletados" (TOMLIN, 1990). Isso significa que as informações geográficas estão georreferenciadas, uma vez que suas coordenadas são conhecidas (IBRAHIN, 2014) e estão associadas a um sistema de coordenadas conhecido (FITZ, 2008).

Existem diversos outros autores também que buscam definir os conceitos da álgebra de mapas e de como tratar da modelagem de dados geográficos. Os autores acabam definindo conceitos que podem ser complementares na análise de dados espaciais. De acordo com Cordeiro et. al. (2007, p. 2):, o tema "álgebra de 
mapas" foi popularizado a partir do livro Geographic Information System and Cartographic Modeling de Tomlin, 1990, que definia os elementos da álgebra de mapas como mapas que "[...] associam a cada local de uma determinada área de estudo um valor quantitativo (escalar, ordinal, cardinal ou intervalar) ou qualitativo (nominal)", ficando o significado da operações a eles aplicadas ao encargo do modelador.

Assim, a álgebra de mapas consiste em um conjunto de procedimentos de análise espacial que produz novos dados por meio de manipulações de dados de um ou mais mapas. A maioria dos operadores de álgebra de mapas está baseada na sobreposição de mapas de uma mesma região coincidentes em escala, localização e projeção cartográfica, o que pode resultar em um novo mapa (VOLL, 2001).

Desta forma, a álgebra se baseia na criação de um novo mapa por meio da reclassificação e sobreposição de dois ou mais mapas. Neste caso, mapas inteiros representam as variáveis, que são processadas espacialmente e o resultado consiste em um mapa com os dados processados. A álgebra de mapas está presente em vários programas de SIG, desde os precursores, como o SYMAP (Synagraphic Mapping System) criado por Fisher em 1971 (BURROUGH, 1986) e outros, como o GRID (ARCINFO), IMGRID e MAP, até os mais populares como GRASS e IDRISI (TOMLIN, 1990). Neste artigo, optou-se em trabalhar com o ARCGIS que apresentou todas as ferramentas necessárias para a execução do estudo. Assim, a seguir a área de estudo do trabalho é apresentada, prosseguida pelos materiais e métodos utilizados no decorrer do estudo, que permitem uma melhor compreensão dos resultados desse trabalho.

\section{Conceituação da área de estudo}

O Parque Nacional do Itatiaia (PNI), o primeiro criado no país em 14 de junho de 1937 (ICMBIO, 2013), é uma UC de proteção integral, e está situado na região Sudeste do Brasil, abrangendo áreas do estado do Rio de Janeiro, nos municípios de Resende e Itatiaia; e ao sul de Minas Gerais, nos municípios Bocaina de Minas e Itamonte (Figura 1). Ocupa atualmente uma área de aproximadamente 30 mil hectares e esta delimitado por um perímetro de cerca de $110 \mathrm{~km}$ (IWAMOTO, 2011; ICMBIO, 2013).

De acordo com o Ministério do Meio Ambiente (portaria no 351/2006), o PNI faz parte do mosaico de UCs da Serra da Mantiqueira (ICMBIO, 2006). Situado na região conhecida como Maciço do Itatiaia, a área onde se insere o PNI é composta pelas seguintes unidades morfoestruturais: Serra do Mar, Vale do Paraíba, Planalto Sul de Minas e Serra da Mantiqueira. Segundo Barros (2003 p.38), o "PNI compreende a segunda região mais elevada da Serra da Mantiqueira, depois da Serra Fina na região de Passa Quatro". São poucas as regiões do Brasil com característica de Montanha, o que confere ao parque grande atratividade perante os visitantes. 


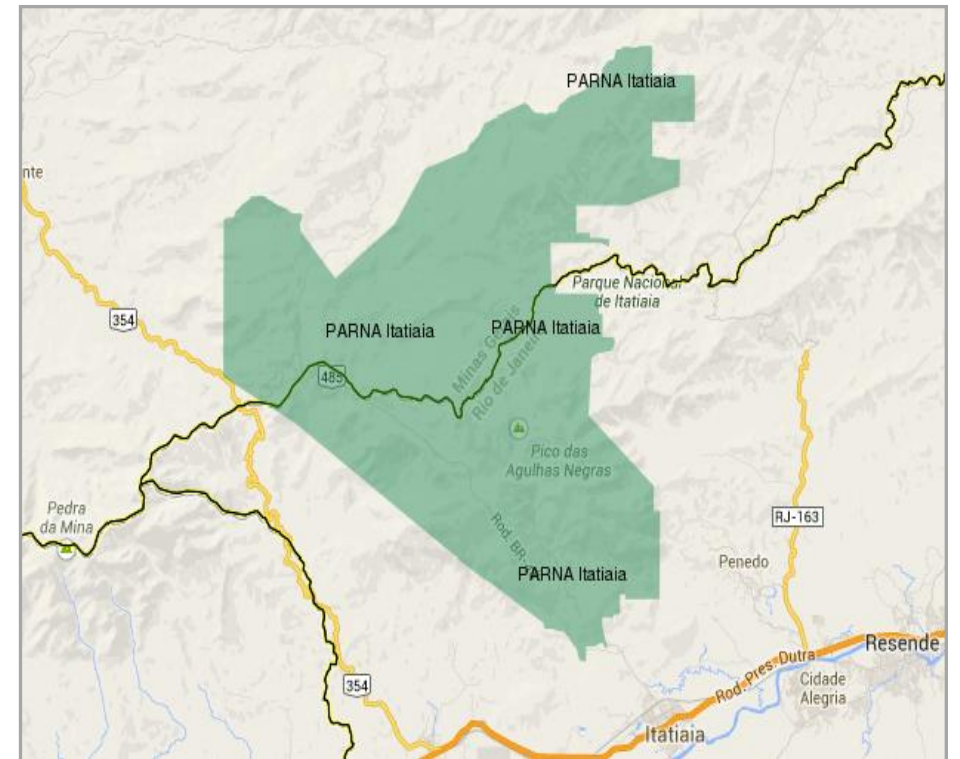

Figura 1: Mapa de localização e limites do Parque Nacional do Itatiaia, RJ.

Fonte: mapas.icmbio.gov.br, 2013.

Figure 1: Location map and boundaries of the Itatiaia National Park, RJ.

Source: mapas.icmbio.gov.br, 2013.

O relevo é caracterizado por montanhas e elevações rochosas, sendo que os principais pontos de altitude são: as Agulhas Negras, com 2787 metros de altitude, sendo o quinto pico mais alto do Brasil; a Pedra do Couto, com 2682 metros; o Pico da Maromba, com 2607 metros; e por último, a elevação de Serra Negra, na margem direita do rio Aiuruoca, que possui 2560 metros de altitude (ARGENTO, 2007). Além das importantes formações rochosas, no parque encontram-se "protegidas várias nascentes formadoras dos rios Aiuruoca, Grande, Preto, Marimbondo, Pirapetinga, Lambari e Portinho" (ARGENTO, 2007). As nascentes são de importantes bacias hidrográficas regionais que drenam para duas bacias de destaque: no Norte para o rio Grande, afluente do rio Paraná, e no Sul para o rio Paraíba do Sul, de grande importância no estado do Rio de Janeiro (ICMBIO, 2014).

O PNI está divido em duas áreas: a "parte baixa" que corresponde à área sul do parque, onde predomina a vegetação de Mata Atlântica e onde são realizadas trilhas curtas que conduzem aos lagos e cachoeiras apropriadas para banho; e a "parte alta", no planalto, onde estão localizadas as Prateleiras (maciço) e o Pico das Agulhas Negras, com vegetação predominante de campos de altitude, principalmente gramíneas que resistem a baixas temperaturas, e onde são realizadas trilhas mais longas e com níveis de dificuldade maiores.

A trilha denominada "Rancho Caído", a qual foi mapeada neste estudo, está localizada na "parte alta" do PNI (Figura 2). A partir do levantamento de campo, que será comentado posteriormente, constatou-se que a trilha apresenta um percurso de aproximadamente $23 \mathrm{~km}$. A seguir pode ser observado o trajeto da trilha na figura 2 de escala 1:70.000 e projeção WGS 1984 UTM, Zone 23S. 


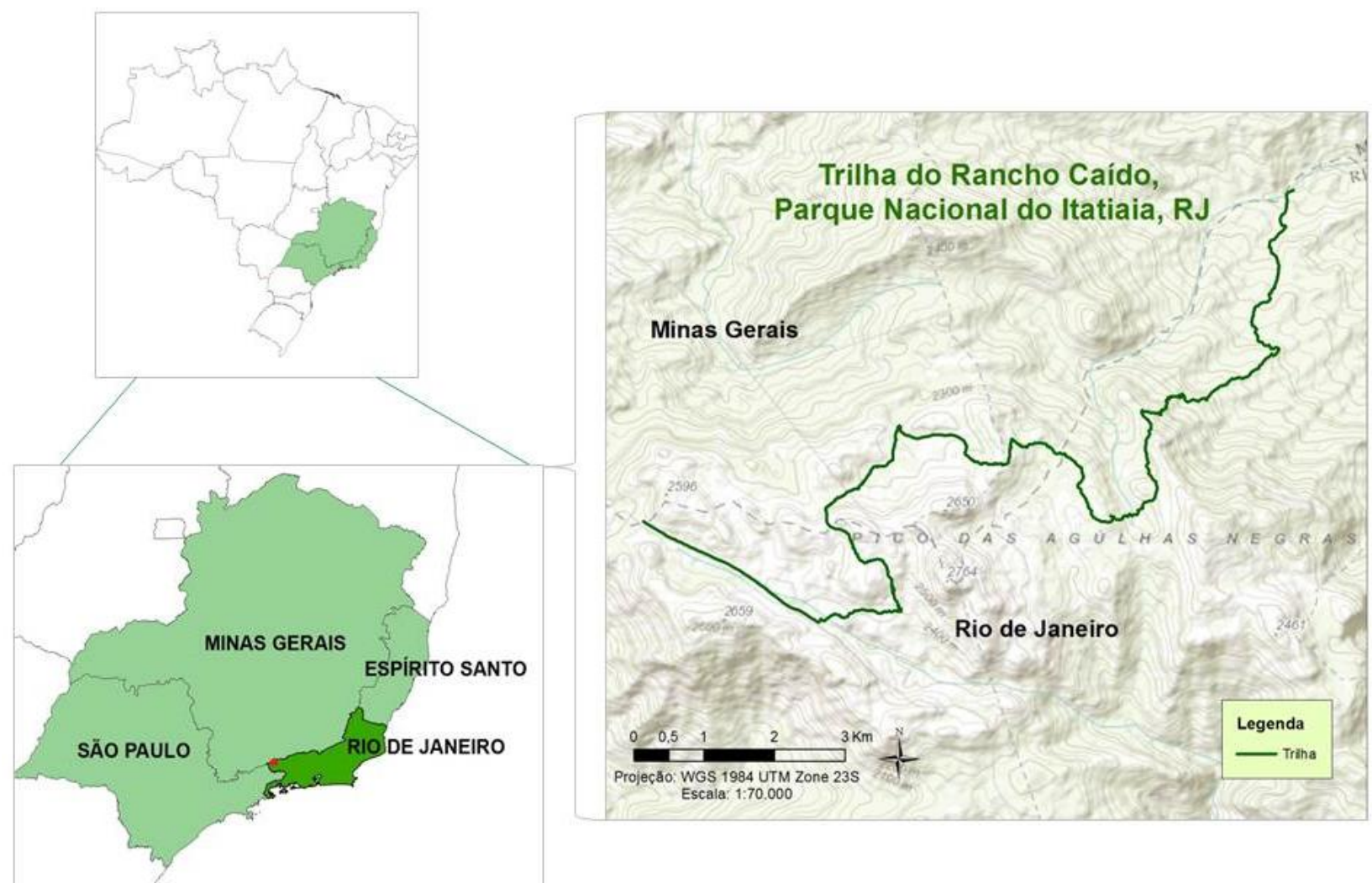

Figura 2: Mapa de localização da trilha do Rancho Caído, PNI, RJ. Fonte: elaboração própria, 2013. Figure 2: Location map of Rancho Caído trail, PNI, RJ. Source: elaborated by authors, 2013.

A trilha do Rancho Caído é considerada uma travessia, sendo também chamada de Travessia Rebouças - Mauá (via Rancho Caído). O nome Rebouças se deve ao fato da existência de um marco na parte alta, o Abrigo Rebouças, local de descanso de muitos montanhistas que frequentam o parque. Mauá se refere ao distrito de Visconde de Mauá, localizado no município de Resende, e ponto de término da travessia. É uma travessia que pode ser feita em até dois dias, com pernoite no Rancho Caído, ou em um dia, sem pernoite. Por normas do parque o início da travessia deve ocorrer até às $10 \mathrm{~h}$.

O itinerário da trilha se inicia no posto Marcão, portão de entrada da parte alta do parque, passando pelo Abrigo Rebouças e segue, primeiramente, o trajeto que leva até a cachoeira do Aiuruoca. Do local segue na direção de outro atrativo, Ovos da Galinha, e prossegue em direção ao vale dos dinossauros (local da nascente do rio Preto). Deste ponto o caminho segue para o Rancho Caído, local utilizado como acampamento por montanhistas que fazem a travessia (coordenadas: latitude $22^{\circ} 21^{\prime} 11^{\prime \prime}$ Sul e longitude $44^{\circ} 38^{\prime}$ '04" W). A partir deste ponto a caminhada prossegue para a região do Mata Cavalo, entrando na mata mais densa, e por fim chega ao distrito de Mauá, sendo que a chegada pode ser pelo Vale das Cruzes ou pela vila de Maromba, próxima à cachoeira do escorrega. A segunda opção foi o caminho mapeado neste trabalho. 


\section{Materiais e Métodos}

O presente estudo foi realizado em três fases, na primeira etapa, a pesquisa bibliográfica e documental compreendeu a coleta de dados em fontes secundárias para levantamentos de dados espaciais e construção do referencial teórico. Na segunda etapa foi feito o levantamento de campo, a trilha foi mapeada com um receptor GPS, modelo Garmin eTrex 30. As coordenadas ou pontos da trilha foram coletados no modo automático, recurso conhecido como tracklog (registro de trajeto) e gravados como trackpoints (pontos do trajeto). Optou-se por realizar o método de gravação das coordenadas no tracklog pelo tempo, utilizandose uma taxa de 1 minuto.

Na terceira etapa foi feito o processamento dos dados e a elaboração dos produtos. Os dados foram descarregados no programa GPSTrackmaker e foram feitos os procedimentos de conexão dos pontos da trilha para determinar a linha do trajeto utilizando como referência uma imagem SRTM do Google Earth. A partir da fotointerpretação foram determinados os trechos da trilha de cada tema ou camada de informação e foi obtida no site do Earth Explorer (USGS) uma imagem SRTM da região do Parque Nacional do Itatiaia ${ }^{3}$.

A projeção cartográfica da imagem obtida da região do PNI é UTM (Universal Transversa de Mercator), datum WGS84, Zona 23 Sul. Os dados foram processados no software ArcGis, tendo como entrada um arquivo raster consistindo na imagem SRTM, e dois arquivos vetoriais, consistindo na linha do trajeto da trilha e nos pontos de água coletados em campo no percurso da trilha. De acordo com a linha do trajeto gerada previamente foi executado um buffer de 100 metros ao redor da trilha, sendo que as análises não foram feitas sobre o espaço do mapa inteiro, mas dentro apenas da zona do buffer. Os buffers são áreas ou corredores de influência gerados em torno de objetos espaciais com distâncias definidas. Procedeu-se a uma extração através de máscara (extrack by mask), consistindo em um processo de recorte da imagem SRTM da seguinte forma: o software faz a leitura do layer com a área do buffer e faz uma extração na imagem SRTM a partir da máscara correspondente à área do buffer.

Com a utilização da imagem SRTM do USGS, o mapa de declividade foi elaborado a partir da ferramenta slope com a determinação das classes de declividade que serão apresentadas a posteriori. Para a elaboração dos mapas de recursos hídricos, cobertura vegetal e qualidade do traçado, foi utilizada a função de edição vetorial do ArcGis para definir polígonos ou trechos dentro do buffer para cada tema, representando as classes de dificuldade definidas qualitativamente, a partir da fotointerpretação feita em imagem SRTM do Google Earth. Dessa forma, foram determinadas as três camadas de informação com estrutura vetorial. Cada camada de informação foi convertida para estrutura raster.

Cada camada temática (declividade, recursos hídricos, cobertura vegetal e qualidade do traçado), referenciada no mesmo sistema de projeção cartográfica, foi reclassificada (ferramenta reclassify) de acordo com os níveis de dificuldade determinados. Na reclassificação é criado um novo mapa por alteração dos atributos dos pixels do mapa original, em que se atribui um novo valor para cada ponto do mapa original. Primeiramente, foram escolhidos três níveis de dificuldade para a reclassificação dos planos de informação, sendo eles: Fácil (1), Moderado (2) e Difícil (3). 
Posteriormente, no produto final, foi determinado um maior número de classes que explicasse com mais fidelidade os níveis de dificuldade da trilha, o que será melhor detalhado em item posterior. As camadas reclassificadas foram somadas pela função weighted overlay e o resultado da soma destas camadas forneceu o mapa temático final. Os produtos deste trabalho consistiram na geração de quatro mapas temáticos, por meio de uma metodologia proposta pelos autores, a qual foi possível gerar uma classificação que considerasse uma maior quantidade de fatores ambientais que influenciam diretamente no esforço físico do usuário da trilha, determinando o nível de dificuldade do trajeto. Os mapas com os níveis de dificuldade de cada tema foram: declividade, recursos hídricos, cobertura vegetal e qualidade do traçado, além do mapa final, com o resultado da soma dos quatro mapas, apresentando os níveis de dificuldade da trilha do Rancho Caído. A seguir são explicados os métodos utilizados para se chegar no mapa de cada tema.

\section{Determinação dos temas e camadas de informação (layers)}

Os fatores a seguir, explicados com maior detalhe posteriormente, foram determinados pelos autores por influenciar na dificuldade de se caminhar por uma trilha: 1. Declividade do terreno, 2. Recursos hídricos, 3. Cobertura vegetal e 4. Qualidade do traçado. Cada fator ou tema representou uma camada de informação (layer). A sobreposição e a realização de operações geográficas com as camadas de informação consistiram na base metodológica deste estudo. Os temas determinados foram sobrepostos em camadas de informação georreferenciadas para o processamento dos dados e geração do produto final. O produto final deste trabalho consistiu no mapa do grau de dificuldade da trilha. Dessa forma, através de uma operação de soma das camadas de informação (declividade, cobertura vegetal, qualidade do traçado e recursos hídricos) foi possível gerar o mapa da classificação quanto ao nível de dificuldade da trilha, considerando todos os fatores propostos. Os itens a seguir melhor descrevem cada tema escolhido.

Declividade: quanto maior a declividade, maior o grau de dificuldade de uma trilha. Neste trabalho foi utilizada a classificação de trilhas adotada por Rocha et al. (2006) em um trabalho realizado no Parque Estadual de Ibitipoca, em Minas Gerais, com a proposta de utilização da rampa média ao longo do percurso da trilha como o principal critério para determinação do grau de dificuldade. No estudo de Rocha et al. (2006), que foi baseado adotando-se as "Normas para Projeto de Rodovias Vicinais" apresentado pelo Banco Nacional de Desenvolvimento Econômico e Social - BNDES,1976, foram propostas as seguintes classes, utilizadas neste trabalho: $0-5 \%$ - relevo plano; $5-20 \%$ - relevo ondulado; $20-70 \%$ relevo montanhoso.

Cobertura vegetal: foram utilizadas duas classes relacionadas à cobertura vegetal: trecho da trilha com cobertura florestal (mata fechada) e trecho da trilha sem cobertura florestal (campo aberto com vegetação rasteira e pequenos arbustos). O caminhar dentro de uma floresta ou por um campo aberto influencia no nível de dificuldade da trilha em decorrência da exposição solar. A exposição ao sol torna a caminhada mais exaustiva, causando mais rapidamente a desidratação. Neste estudo foi considerado que o caminhar em uma mata fechada possui um nível de dificuldade fácil por ser um lugar de sombra. De forma contrária, o caminhar em um campo aberto, devido à exposição solar, torna moderado ou difícil o grau de dificuldade da trilha. 
Recursos hídricos: durante a caminhada o corpo necessita de hidratação. Se o corpo fica muito tempo sem reposição hídrica, isso ocasiona uma diminuição no desempenho da tolerância ao exercício do corpo, o que torna a caminhada mais difícil. A necessidade de consumo de água varia de indivíduo para indivíduo, sendo influenciada pelas condições ambientais e pelas características da atividade física, que neste estudo trata-se de uma caminhada de longo percurso. A perda de água pelo corpo é bastante variável, mas pode atingir até dois litros por hora. Segundo diretrizes da Sociedade Brasileira de Medicina Esportiva, no caso de uma atividade física em que haja exposição solar, em um ambiente mais quente, recomenda-se a ingestão de $500 \mathrm{ml}$ a 2 litros de água por hora, sendo indicado a ingestão de líquido durante a atividade a cada 15 a 20 minutos (CARVALHO, 2010). Assim, considerou-se, neste estudo, que um indivíduo deve carregar cerca de 2 litros de água consigo e em velocidade média caminha cerca de $3 \mathrm{~km} / \mathrm{h}$, ou seja, uma distância adequada para se repor a água em algum ponto do percurso. Logo, foram determinados trechos ao longo da trilha onde fosse possível o abastecimento de água. Dessa forma, adotou-se como trechos considerados com nível de dificuldade fácil aqueles nos quais se encontravam pontos de água com facilidade ao longo do trajeto. Em locais da trilha em que a distância de um ponto de água ao outro superava $3 \mathrm{Km}$ de distância, o trecho foi considerado difícil.

Qualidade do traçado: o desenho da trilha deve ser determinado de forma a evitar obstáculos como pedras, poças de lama e troncos caídos, e evitar um terreno com problemas de drenagem do solo, em que pontos da água cruzem à trilha ou esteja na mesma direção da trilha (ANDRADE et al., 2008). A consideração desses fatores na determinação do traçado da trilha pode evitar que futuramente haja um desvio na rota. Esses fatores influenciam no caminhar do visitante, fazendo com que maior energia seja dispensada em trechos em que haja muitos obstáculos e que o solo seja pouco coeso. Dessa forma, foram determinados trechos em que a qualidade do traçado torna a trilha difícil por apresentar obstáculos ou pela má drenagem do solo.

\section{Resultados e discussões}

Os produtos deste trabalho consistiram na geração de quatro mapas temáticos com os níveis de dificuldade de cada tema: declividade, recursos hídricos, cobertura vegetal e qualidade do traçado, além do mapa final, com o resultado da soma dos quatro mapas, apresentando os níveis de dificuldade da trilha do Rancho Caído. A seguir é explicada detalhadamente a geração de cada mapa, nos quais foram utilizadas o padrão de cores: verde, amarelo e vermelho para observação dos trechos fáceis, médios e difíceis respectivamente.

O mapa de declividade foi feito a partir de um recorte ou clip na imagem SRTM original, na escala de 1: 250.000, para delimitar e trabalhar apenas com a região de relevância ao redor da trilha (situado a X Min $=522.000 / X$ Max $=548.000$ / Y Min 7.515.000 / Y Max = 7.538.000), com a sobreposição da linha da trilha (já referenciada na mesma projeção cartográfica) na imagem SRTM, com escala 1:70.00. Esse mapa foi gerado a partir da função slope do ArcGis, em que foram determinados os intervalos de declividade a serem utilizados no fatiamento e nas classes temáticas. O mapa de declividade tem o objetivo de demonstrar as inclinações de uma área em relação a um eixo horizontal. O slope calcula o máximo valor de mudança entre uma célula e suas vizinhas. Esse valor pode ser chamado 
de valor "z" (z-value). O slope pode ser calculado com as classes de declividade em porcentagem ou em graus. Neste trabalho foram utilizadas as classes em porcentagem, sendo : 0-5\% - fácil; 5-20\% - moderado, e 20-70\% - difícil.

Antes da geração do mapa de declividade, foi feita uma reamostragem dos pixels de 5 metros por interpolação bilinear, permitindo uma maior precisão geométrica do mapa e o desaparecimento de descontinuidades. No método da interpolação bilinear é calculada a média ponderada das distâncias dos centros dos 4 pixels ao centro do pixel de saída. O cálculo do pixel de saída é dado pela distância entre dois pixels (de entrada), em que é efetuada uma aproximação por uma equação linear.

A área redimensionada correspondeu a um mapa na escala 1:70.000. Foi feita uma reclassificação das classes de declividade, permitindo posteriormente a soma (weighted overlay) de cada camada de informação. O mapa de declividade (Figura 3) permitiu observar as classes de declividade em cada trecho da trilha.

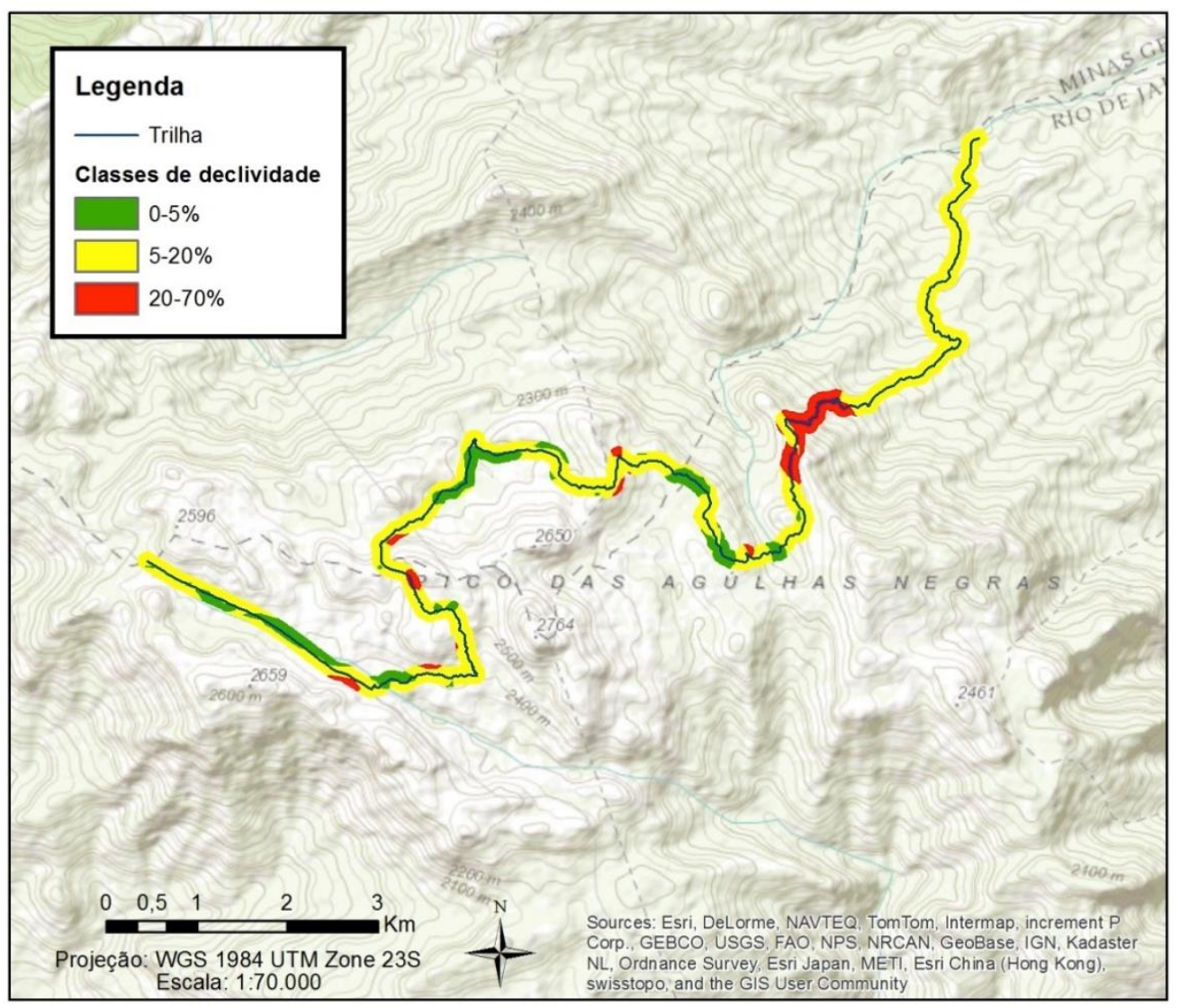

Figura 3: Mapa de declividade da trilha. Fonte: os autores, 2013.

Figure 3: Slope trail map. Source: elaborated by authors, 2013.

Para a realização do mapa de recursos hídricos, como observado anteriormente, foi utilizado um valor referência de $3 \mathrm{~km}$ entre dois pontos de água como distância máxima. Desta forma, quando uma distância entre dois pontos de água ultrapassa $3 \mathrm{~km}$, considera-se que o ser humano necessita consumir mais água, em decorrência do maior esforço e de dificuldades nesses determinados trechos da trilha. Após a criação dos polígonos, na edição vetorial, dentro do buffer do mapa de recursos hídricos, foi feita a reclassificação dos trechos: fácil, com menos de $3 \mathrm{~km}$ entre dois pontos de água, havendo pontos de água; e difícil, com mais de $3 \mathrm{~km}$ entre dois pontos, não se encontrando pontos de água. O mapa de 
recursos hídricos (Figura 4) ilustra essas informações, permitindo observar os pontos de água e os trechos correspondentes à disponibilidade ou necessidade de água e à dificuldade resultante (indicada na cor vermelha).

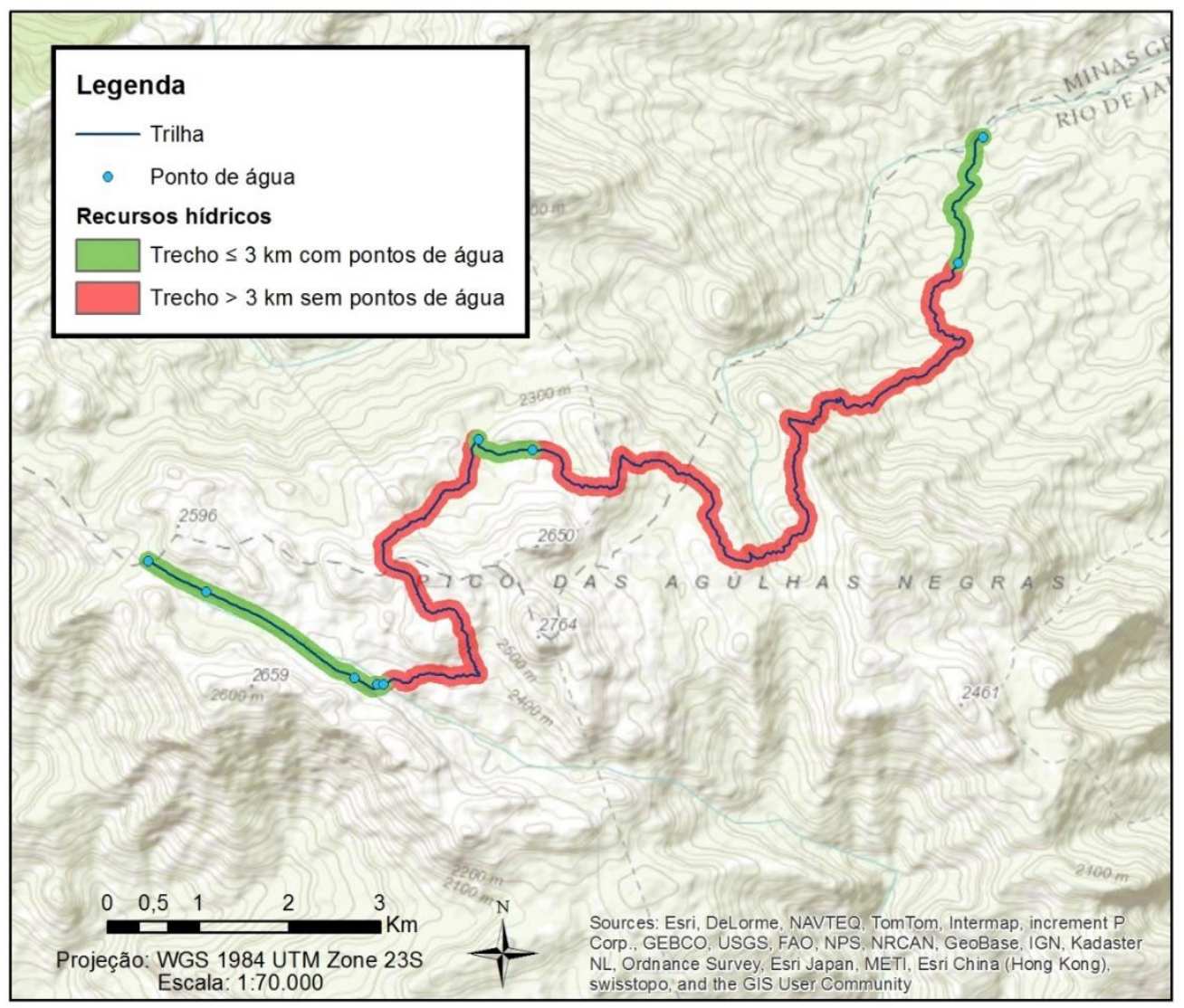

Figura 4: Mapa de recursos hídricos da trilha. Fonte: os autores, 2013.

Figure 4: Water resources map of the trail. Source: elaborated by authors, 2013.

Para a elaboração do mapa e dos trechos relativos à qualidade do traçado, foram observados no Google Earth os lugares a partir dos quais o caminho da trilha muda seus aspectos físicos, apresentando mais obstáculos e se tornando um caminho mais ou menos estável e fácil de se locomover, conforme visto anteriormente. A partir da fotointerpretação foi possível a elaboração de polígonos correspondentes à dificuldade de cada trecho, levando em conta a qualidade do traçado do caminho, o que permitiu a reclassificação. O mapa do traçado (Figura 5) ilustra essas informações, apresentando os trechos em função da dificuldade causada pelas mudanças do terreno. 


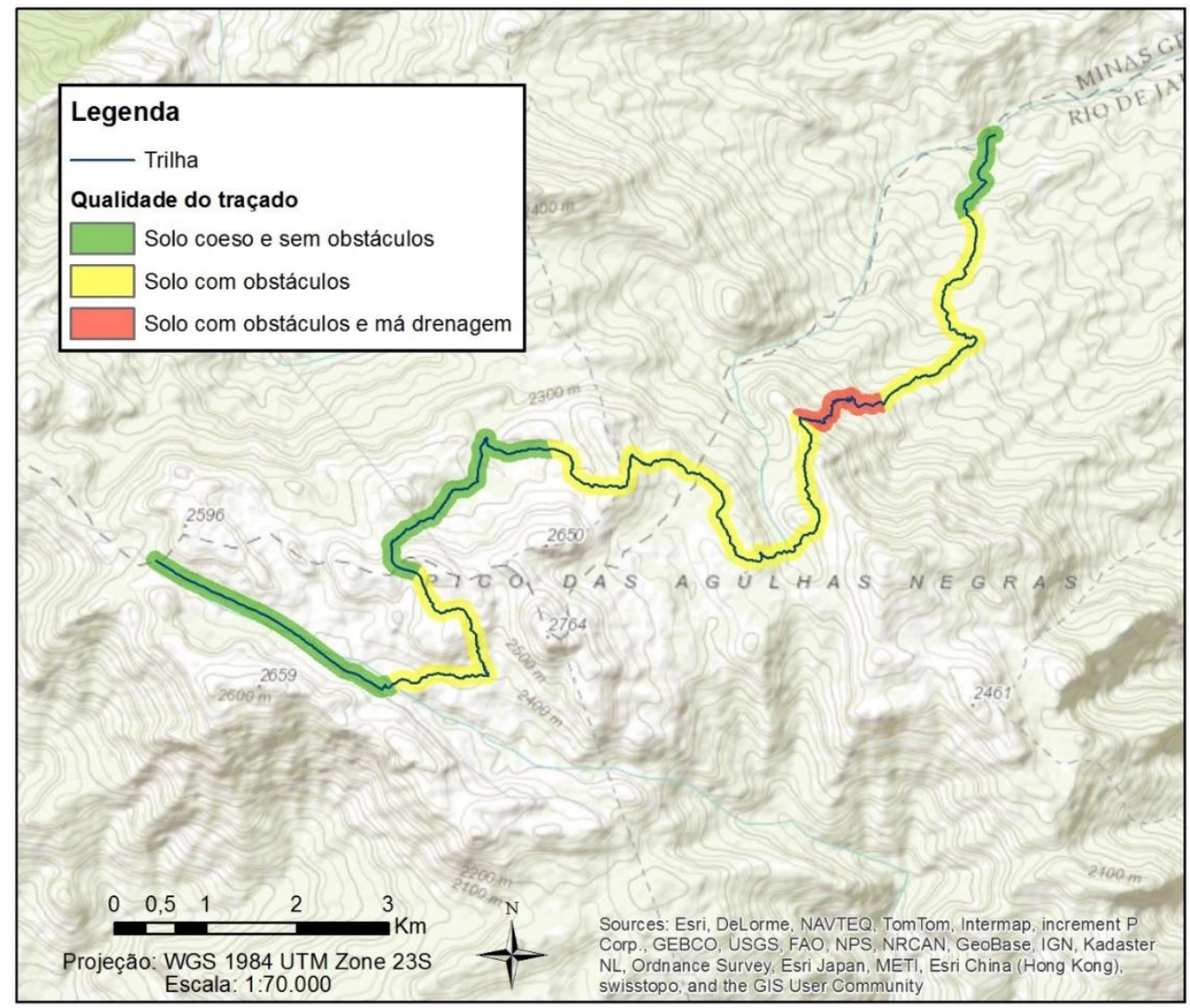

Figura 5: Mapa do traçado da trilha. Fonte: os autores, 2013.

Figure 5: Route map of the trail. Source: elaborated by authors, 2013.

Para a elaboração do mapa relativo à cobertura vegetal, foram determinados os trechos a partir da observação da imagem do percurso no Google Earth. Observou-se o limite a partir do qual a trilha passa de um caminho aberto, fortemente exposto ao sol, a um caminho protegido, com Mata Atlântica fechada, e que cria uma barreira natural para o sol. Conforme observado anteriormente, caminhar em uma trilha de ambiente exposto ao sol pode ser classificado como algo difícil, enquanto que caminhar em trechos com proteção de cobertura vegetal pode ser classificado como algo mais fácil. A partir dessas informações foi possível elaborar polígonos correspondentes aos trechos com ou sem cobertura florestal, seja com ou sem exposição ao sol. O mapa de cobertura vegetal (Figura 6) apresenta essa diferenciação e a dificuldade resultante.

Conforme explicado anteriormente relativo à álgebra de mapas, a realização do mapa temático final de dificuldades representou a sobreposição ou soma dos quatro mapas precedentes (declividade, recursos hídricos, qualidade do traçado e cobertura vegetal). A função do ArcGis utilizada para realizar a operação de soma dos mapas foi weighted overlay. Essa ferramenta realiza a soma de vários arquivos raster de entrada, através de valores atribuídos ao conjunto de pixels (classes temáticas ou intervalos de valores, no caso da declividade), somando os pixels de cada mapa que possuem a mesma localização espacial.

Os valores devem ser números inteiros e podem ser atribuídos no momento da execução da ferramenta weighted overlay ou antes pela ferramenta de reclassificação (reclassify), como feito neste trabalho. Essa ferramenta também permite atribuir pesos para determinar os arquivos raster com maior importância 
relativa para o resultado final. Os pesos atribuídos a cada mapa são, então, multiplicados aos valores dos pixels, procedendo-se à soma dos pixels de mesma posição em cada matriz. Neste estudo optou-se pela não atribuição de pesos aos temas.

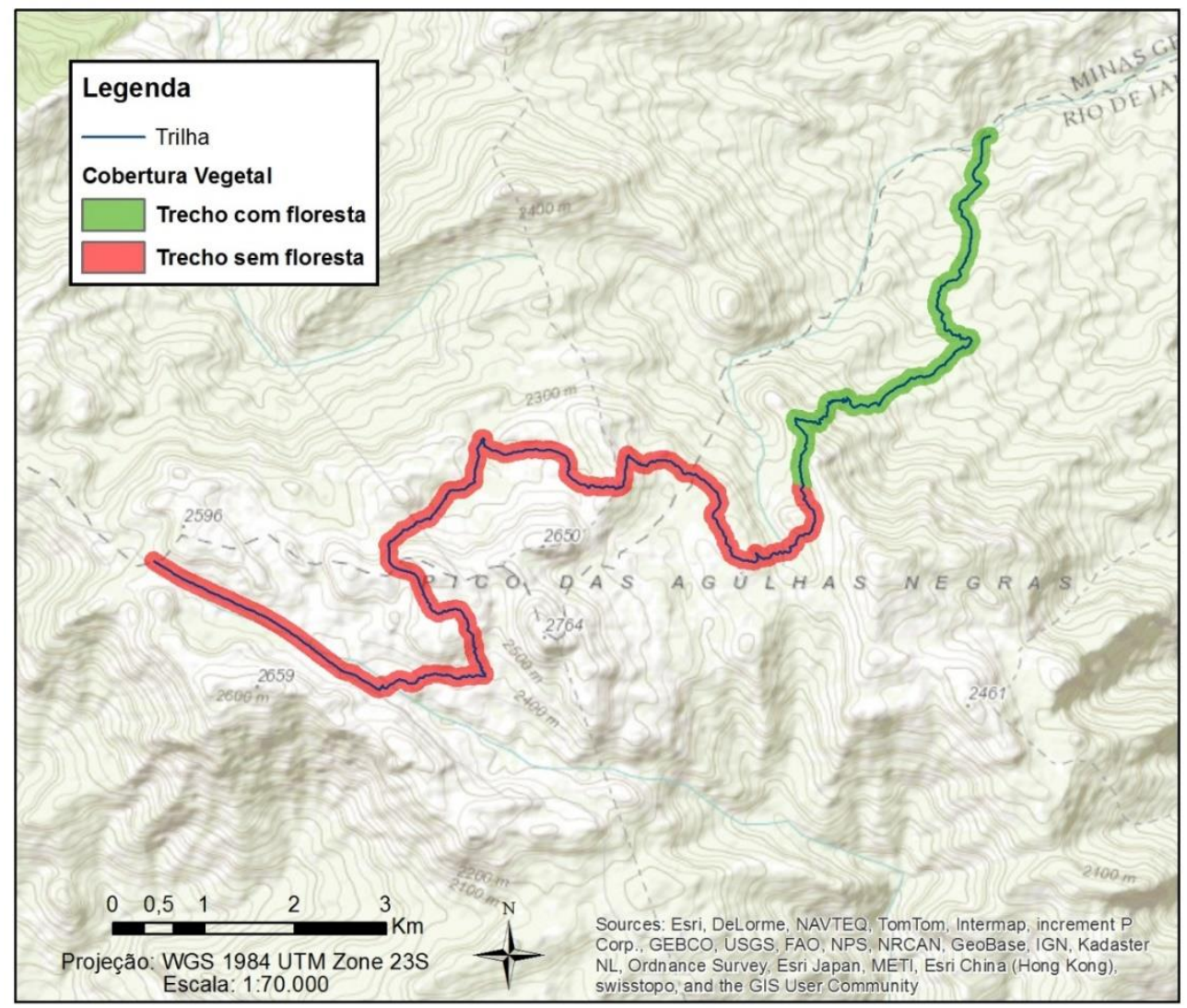

Figura 6: Mapa de cobertura vegetal da trilha. Fonte: os autores, 2013.

Figure 6: Vegetation cover map of the trail. Source: elaborated by authors, 2013.

Com o intuito de melhor apresentar os resultados obtidos com a reclassificação do grau de dificuldade de cada tema e a geração do mapa final, foram desenvolvidas matrizes temáticas. O objetivo foi de combinar as classes de todos os temas dentro de uma matriz de maneira a estabelecer as categorias de dificuldade. A análise integra quatro fatores de entrada, correspondendo aos quatro temas, sendo que o objetivo foi estabelecer uma matriz de representação geral (o que significa duas entradas), sendo necessário desenvolver duas tabelas intermediárias cruzando as informações de cada tema.

Dois desses temas apresentaram classes de 1 a 3 e os dois outros apresentaram classes com os valores 1 e 3 . Para permitir uma melhor leitura da matriz final, representando todos os resultados que foram possíveis encontrar no mapa, foi decidido cruzar os temas apresentando as classes de 1 a 3 (três classes) com temas apresentando as classes com os valores 1 e 3 (duas classes), assim as matrizes apresentariam absolutamente todos resultados possíveis. As duas primeiras tabulações cruzadas foram somente uma etapa intermediária permitindo a criação da tabulação cruzada final, sendo que as conclusões foram estabelecidas somente através da matriz final. Apesar da escolha do cruzamento entre temas com o número distinto de classes, a escolha dos dois primeiros cruzamentos foi aleatória. 
Primeiramente foi elaborada uma matriz de classificação da declividade versus os recursos hídricos. Em seguida foi elaborada uma matriz de classificação da cobertura vegetal versus a qualidade do traçado. Por fim foram consolidas em uma única matriz as informações referentes às matrizes de classificação dos temas. A partir do cruzamento das matrizes de classificação foi possível definir todos valores representativos dos diferentes níveis de dificuldade da trilha. Com a adição dos valores referentes a dificuldade de cada fator, o mapa final apresenta graus de dificuldades que variam de 4 e 12.

Para permitir uma leitura mais precisa das informações e ter uma maior visibilidade da representação da dificuldade, foi realizada uma nova classificação dos valores atuais de 5 classes - muito fácil, fácil, moderado, difícil, muito difícil. A média é de aproximadamente 8 , sendo que foi escolhido o valor 8 como limite entre a classe intermediária (moderado) e a superior (difícil). Para poder obter uma dispersão de valor igual, foi escolhido um intervalo de 1,5 entre cada classe, com exceção da primeira (4-5 - intervalo de 1). No caso da última classe, o intervalo teórico é de 2,5 (9,5-12) porque a adição dos 4 valores máximos (3) resulta em um valor máximo potencial de 12 . O intervalo real é também de 1,5 , porque o valor máximo encontrado é de 11. Assim, obteve-se uma nova classificação precisa permitindo uma ilustração clara do nível de dificuldade apresentado pela trilha, conforme se observa na tabela 1 a seguir:

\begin{tabular}{|c|c|}
\hline \multicolumn{2}{|c|}{ Classes de níveis de dificuldade da trilha } \\
\hline $4-5$ & Muito fácil \\
\hline $5-6,5$ & Fácil \\
\hline $6,5-8$ & Moderado \\
\hline $8-9,5$ & Difícil \\
\hline $9,5-12$ & Muito difícil \\
\hline
\end{tabular}

Tabela 1: Classificação de níveis de dificuldade da trilha. Fonte: os autores.

Table 1: Trail difficulty levels rating. Source: elaborated by authors.

O mapa ilustrado na figura 7 consiste no produto final deste estudo. Foram utilizadas cinco classes representantes dos níveis de dificuldade da trilha, quais sejam: Muito fácil (4-5), Fácil (5-6,5), Moderado (6,5-8) e Difícil (8-9,5), conforme definido e apresentado na Tabela 1. Cada classe foi representada espacialmente, ou seja, de forma gráfica constituindo o mapa temático dos níveis de dificuldade da trilha do Rancho Caído, também conhecida como Travessia Rebouças - Mauá via Rancho Caído. 


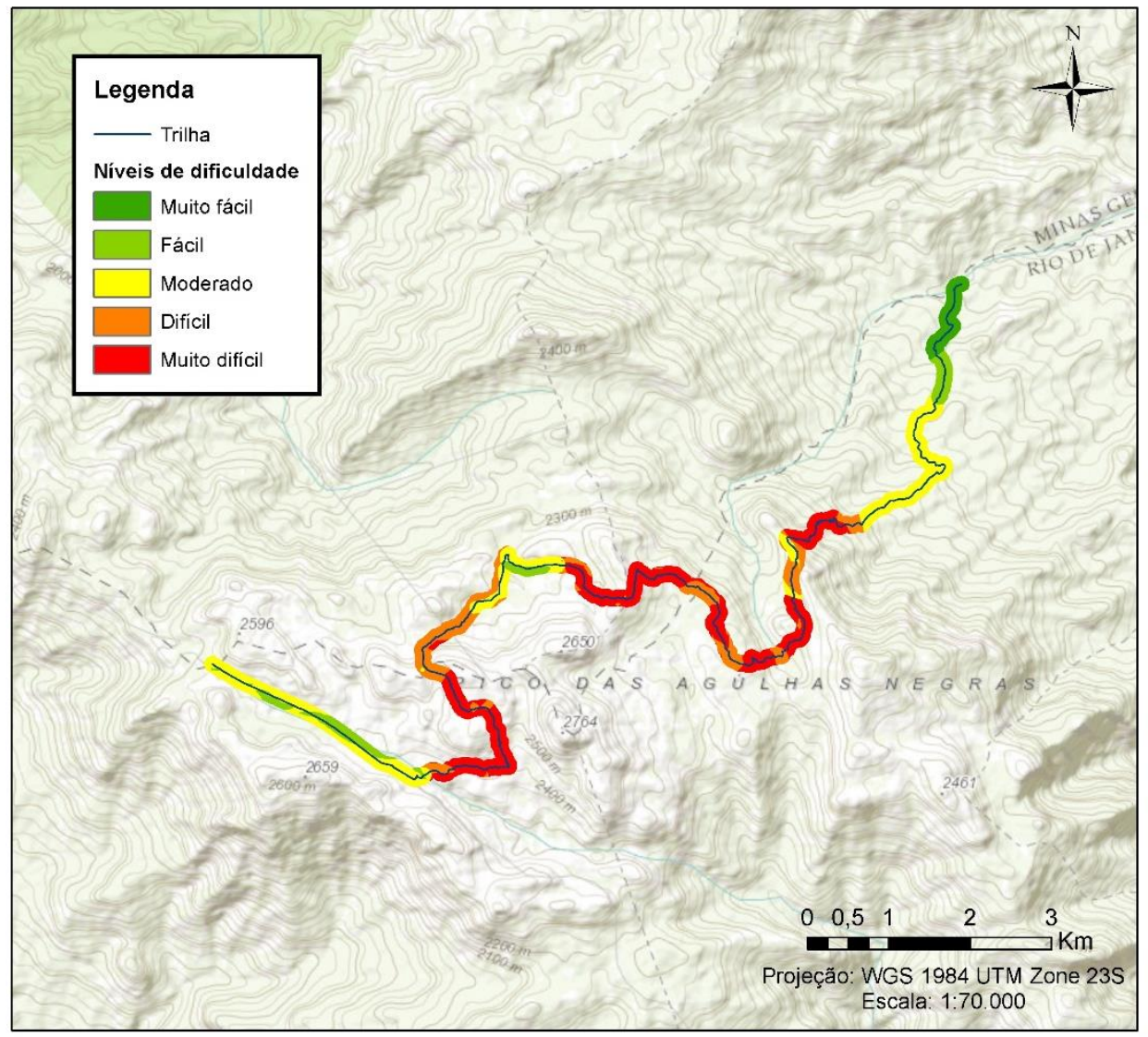

Figura 7: Mapa com os níveis de dificuldade da trilha do Rancho Caído. Fonte: os autores, 2013.

Figure 7: Map of Rancho Caído trail difficulty levels.Source: elaborated by authors, 2013.

As tonalidades na cor verde representam os trechos com níveis de dificuldade "muito fácil" e "fácil". As tonalidades de amarelo a vermelho representam os trechos com níveis de dificuldade "moderado", "difícil" e "muito difícil". Observouse ao término do estudo que apesar dos mapas temáticos de cada tema terem tido uma definição clara dos trechos de dificuldades, ao serem realizadas as sobreposições e terem sido criadas as matrizes de classificação geral, houve trechos com uma leve variação dos níveis de dificuldade, o que se observa pela sobreposição e tonalidades diferentes dentro de um mesmo espaço. Fato este que pode ser ajustado no sistema a partir da criação de novas classes e delimitação de novos temas.

\section{Considerações finais}

Essa pesquisa teve como principal objeto de estudo a trilha do Rancho Caído, caracterizada como travessia, que se inicia na parte alta do Parque Nacional do Itatiaia e sua chegada é próxima à cachoeira do escorrega, na vila de Maromba, no distrito de Visconde de Mauá, em Resende. O trabalho fundamentou-se principalmente nos conceitos e ferramentas dos SIG, bem como na álgebra de mapas.

A partir da aplicação de técnicas de análise espaciais do SIG foi possível a elaboração de quatro mapas temáticos distintos e que, posteriormente, por uma operação de sobreposição (overlay), do tipo adição, foram somados constituindo um mapa temático dos níveis de dificuldade da trilha. Esta foi a principal base teórica para o desenvolvimento deste trabalho. Para a delimitação dos quatro temas 
ou camadas (layers) foram utilizados fatores que contribuem para a dificuldade da trilha, sendo a declividade, recursos hídricos, cobertura vegetal e qualidade do traçado. Esses fatores ambientais foram determinados de acordo com a experiência dos autores e com embasamento em alguns estudos relacionados a trilhas.

Para cada tema foram criadas classes de dificuldade que constituíram a matriz de classificação, a qual permitiu a definição de classes de dificuldades para o mapa temático final. Assim, os resultados do trabalho foram o mapeamento da trilha e a produção de um mapa temático com os níveis de dificuldade da trilha.

Interessante ressaltar que os levantamentos em campo foram feitos no ano de 2013, época em que não havia mapeamento da trilha selecionada para estudo. No início do ano de 2014 foi liberado o plano de manejo do Parque Nacional do Itatiaia para o público em geral, no qual há indicações sobre o mapeamento básico das trilhas. Em visita ao parque no segundo semestre de 2014, foi possível observar algumas placas com mapas de orientação, indicando o tamanho do percurso de trilhas, pontos de interesses e o grau de dificuldade de trilhas, de acordo com o tamanho do percurso e declividade.

Diante disso, a principal contribuição deste artigo foi o desenvolvimento de uma metodologia, com embasamento na álgebra de mapas, levando em conta outros fatores ambientais que podem auxiliar na determinação do grau de dificuldade de trilhas. Espera-se que o presente estudo sirva de referência para outros trabalhos acadêmicos, bem como possa ser acrescido de novas ideias e aprimorado com o avanço de estudos. Essa metodologia pode ser explorada em maior profundidade por outros acadêmicos, pesquisadores e profissionais, da mesma forma, outros temas podem ser considerados nesta metodologia, de acordo com o conhecimento de "experts" em trilhas.

\section{Referências bibliográficas}

ANDRADE, W. J. Implantação e manejo de trilhas. In: MITRAUD, S.(org). Manual de Ecoturismo de Base Comunitária: ferramentas para um planejamento responsável. WWF Brasil, 2003. 470p.

ANDRADE,W. J.; ROCHA, R.F. Manejo de trilhas: um manual para gestores. IF, Série Registros, São Paulo, n. 35, p. 1-74, maio 2008.

ARCHELA, R.S.; THÉRY, H. Orientation méthodologique pour la construction et la lecture de cartes thématiques. Revue Franco-Brésilienne de Géographe. Número 3 , 2008. Disponível em: < http://confins.revues.org/>. Acesso em: 29 set. 2013.

ARGENTO, M.S.F.; FERNANDES, M.C.; SILVA, L.C.V. Modelagem ambiental de cenários de potencialidade a ocorrência de incêndios no Parque Nacional do Itatiaia/RJ. Anais XIII Simpósio Brasileiro de Sensoriamento Remoto, Florianópolis, Brasil, 21-26 abril 2007, INPE, p. 3117-3124.

ARONOFF, S. Geographic Information Systems: a management perspective. Ottawa: WDL Publications, 1991. 294p.

BARROS, M.I.A. Caracterização da visitação, dos visitantes e avaliação dos impactos ecológicos e recreativos do planalto do Parque Nacional do Itatiaia, 2003. Dissertação (mestrado) apresentada à Escola Superior de Agricultura Luiz da Universidade de São Paulo, Piracicaba. 121p. 2003. 
BERRY, J.K. Assessing Spatial Impacts of Land Use Plans. Journal of Environmental Management, v.27, p.1-9, 1988.

BERRY, J.K. Cartographic modeling: the analytical capabilities of GIS. In: GOODCHILD, M.F.; PARKS, O.B.; STEYAERT, L.T. Environmental modeling with GIS. New York: Oxford University Press, 1993.

BURROUGH, P.A. Principles of Geographical Information Systems of Land Resources Assessment. Clarendon Press, Oxford University Press. Oxford, 1986. $193 p$.

BWF - BRITISH WALKING FEDERATION. Trail Grades. Disponível em: $<$ http://www.bwf-ivv.org.uk/about/Registration/Trail\%20Grades.html>. Acesso em: nov. 2014.

CÂMARA, G. et al. Introdução à ciência da Geoinformação. Instituto Nacional de Pesquisas Espaciais, São José dos Campos, SP, 2001.

CÂMARA, G. Modelos, Linguagens e arquiteturas para Bancos de Dados Geográficos. 1995. Tese (Doutorado em Computação Aplicada) - Instituto Nacional de Pesquisas Espaciais, São José dos Campos, SP, 1995.

CARVALHO, T. MARA, L. Hidratação e Nutrição no Esporte. Revista Brasileira de Medicina do Esporte, v.16, n.2, Niterói, RJ, mar/apr., 2010.

CORDEIRO, J.P; BARBOSA, C.C.F.; CÂMARA, G. Análise Espacial de Dados Geográficos. Instituto Nacional de Pesquisas Espaciais, São José dos Campos, SP, 2007.

COSTA, P. C. Unidades de Conservação: matéria-prima do ecoturismo. São Paulo: Aleph, 2002.

COSTA, V. C. Proposta de manejo e planejamento ambiental de trilhas ecoturísticas: um estudo do Maciço da Pedra Branca, município do Rio de Janeiro (RJ), 2006. Tese (Doutorado em Ciências, Geografia) apresentada à Universidade Federal do Rio de Janeiro, Rio de Janeiro, 2006.

COSTA, V.C.; TRIANE, B.P.; COSTA, N.M.C. Impactos ambientais em trilhas: agricultura X Ecoturismo - um estudo de caso na Trilha do Quilombo (PEPB-RJ). Revista Brasileira de Ecoturismo, São Paulo, v.1, n.1, 2008, p.84-113.

COWEN, D.J. GIS versus CAD versus DBMS: what are the differences? Protogrammetric Engineering and Remote Sensing, v.54, n.11, p.1551-1555, nov. 1988.

DIAS, A.C.; MOURANETTO, B.V.; MARCONDES, M.A.P. Trilha interpretativa do rio Taquaral - Parque Estadual de Carlos Botelho. Boletim Técnico IF, v. 40-A, p. 11-32, 1986, pt. 1, Edição especial.

EARTH EXPLORER - USGS. Imagem SRTM. Disponível em: $<$ http://earthexplorer.usgs.gov/>. Acesso em: ago. 2014.

FEMERJ - FEDERAÇÃO DE MONTANHISMO DO ESTADO DO RIO DE JANEIRO. Proposta para Classificação de Trilhas para o Estado do Rio de Janeiro. Novembro, 2014. Disponível em: <http://www.femerj.org/>. Acesso em: jan. 2015.

FERREIRA, N.C. Sistema de Informações Geográficas. Coordenação da Área de Geomática, do Centro Federal de Educação Tecnológica do Estado de Goiás, Goiânia. 113p. 2006. (Apostila). 
FITZ, P.R. Geoprocessamento sem complicação. São Paulo: Oficina de textos, 2008.

GOODCHILD, M.F. Geographical data modeling. Computers \& Geosciences, London, v.18, n.4, p.401-408, 1992.

GOODCHILD, M.F. The State of GIS for Environmental Problem-Solving. In: GOODCHILD, M.F.; PARKS, O. B.; STEYAERT, L. T. Environmental modeling with GIS. New York: Oxford University Press, p. 8-15, 1993.

Hugo, M.L. Energy Equivalent as a measure of the difficulty rating of hiking trails. Tourism Geographies, v.1, n.3, p. 1-15, 1999.

IBRAHIN, F.I.D. Introdução ao geoprocessamento ambiental. 1 ed. São Paulo: Érica, 2014.

ICMBIO - INSTITUTO CHICO MENDES DE CONSERVAÇÃO DA BIODIVERSIDADE. Sistema Nacional de Unidades de Conservação. Volume 1. ICMBio, Agosto de 2009. (Série Legislação ICMBio).

ICMBIO - INSTITUTO CHICO MENDES DE CONSERVAÇÃO DA BIODIVERSIDADE. Mosaico de Unidades de Conservação Serra da Mantiqueira - Mosaico Mantiqueira. Portaria oㅜ 351, de 11 de dezembro de 2006.

ICMBIO - INSTITUTO CHICO MENDES DE CONSERVAÇÃO DA BIODIVERSIDADE.

Parque Nacional do Itatiaia. Disponível em: <
http://www.icmbio.gov.br/parnaitatiaia/>. Acesso em: ago 2014.

ICMBIO - INSTITUTO CHICO MENDES DE CONSERVAÇÃO DA BIODIVERSIDADE. Plano de Manejo do Parque Nacional do Itatiaia. Volume 1. Brasília, DF, 2013.

IWAMOTO, P.K.; RODRIGUES, M.G. Uma proposta de delimitação da zona de amortecimento do Parque Nacional do Itatiaia, Rio de Janeiro, Brasil. Revista Nordestina de Ecoturismo. Aquidabã, v.4, n.2, p.5-14, 2011.

KINKER, S. Ecoturismo e conservação da natureza em parques nacionais. Campinas, SP: Papirus, 2002. Coleção Turismo.

MITRAUD, S. (org). Manual de Ecoturismo de Base Comunitária: ferramentas para um planejamento responsável. WWF Brasil, 2003. 470p.

NT - THE PARKS AND WILDLIFE SERVICE. Walks, Talks and Trails. Disponível em: $<$ http://www.parksandwildlife.nt.gov.au/>. Acesso em: nov. 2014.

NTO - THE NATIONAL TRAILS OFFICE. A Guide to Planning and Developing Recreational Trails in Ireland. 1st Edition February, 2012.

ROCHA, C.H.B. et al. Mapeamento e classificação de trilhas em parques florestais com uso do GPS: aplicação no Parque Estadual de Ibitipoca/MG. Juiz de Fora: COBRAC, 2006.

ROSA, M.R.; ROSS, J.L. Aplicação de SIG na Geração de Cartas de Fragilidade. Revista do Departamento de Geografia, v. 13, FFLCH-USP, 1999.

SALVATI, S.S. Trilhas: conceitos, técnicas de implantação e impactos. Ecosfera, artigo publicado em: <http://ecosfera.sites.uol.com.br/trilhas.htm>. Publicado em 21 set. 2003. 3p.

SCOTLAND'S NATIONAL TOURISM ORGANISATION. Walking Trail Grades. Disponível em: $<$ http://scotland.forestry.gov.uk/activities/walking/walking-trail-grades $>$. Acesso em: nov. 2014. 
SPINOLA, C.A. Parques Nacionais, Conservação da Natureza e Inserção Social: uma realidade possível em quatro exemplos de cogestão. Revista Turismo Visão e Ação - Eletrônica, v. 15, n. 1, p. 71-83, jan-abr. 2013.

TOMLIN, D. Geographic information systems and Cartographic Modeling. Prentice Hall, New York, 1990.

VOLL, E. Carta de Vulnerabilidade Natural da Região do Bico do Papagaio - TO. 2001. Especialização (Especialista em Geoprocessamento) - Universidade Federal de Minas Gerais, Minas Gerais, 2001.

\section{Notas}

${ }^{1}$ CEBALLOS-LASCURÁIN, Héctor. Estudio de Prefactibilidad Socioeconómica del Turismo Ecológico y Anteproyecto Arquitectónico y urbanístico del Centro de Turismo Ecológico de la Reserva de la Biósfera Sian Ka'an, Q.R.; México. Estudio para SEDUE, México, DF, 1987.

2 Os dados raster são dados que apresentam uma estrutura matricial, ou seja, são representados por uma matriz, na qual cada célula que é chamada de pixel possui seu valor específico que pode indicar uma cor ou tom de cinza. Nas imagens georreferenciadas, cada pixel apresenta um par de coordenadas planas e/ou geográficas. Há também os dados do tipo vetorial que são representados por pontos, linhas e polígonos e que utiliza um sistema de coordenadas para sua representação (FITZ, 2008).

${ }^{3}$ A sigla SRTM significa, em tradução para o português, Missão Topográfica por Radar do Ônibus Espacial, consistindo em uma operação projetada e financiada pela Agência Espacial Americana (NASA) para adquirir dados de altimetria de todo o globo terrestre a partir de sensores ativos (radar). A resolução original das imagens SRTM é de 30 metros; no entanto, para a América do Sul a NASA liberou imagens com resolução de 90 metros

Grislayne Guedes Lopes da Silva: Universidade de São Paulo, São Paulo, SP, Brasil. E-mail: gris-guedes@gmail.com

Link para o currículo Lattes: http://lattes.cnpq.br/1473848485735432

Thalita Campos Lima: Universidade de São Paulo, São Paulo, SP, Brasil.

E-mail: thalitacl@hotmail.com

Léandre Panchaud: Centro Universitário Senac, São Paulo, SP, Brasil.

E-mail: leandre@ifesp.com.br

Link para o currículo Lattes: http://lattes.cnpq.br/5413472763372123

Data de submissão: 19 de fevereiro de 2015

Data de recebimento de correções: 04 de maio de 2016

Data do aceite: 04 de maio de 2016

Avaliado anonimamente 